\title{
Amyloid mis-metabolism in idiopathic normal pressure hydrocephalus
}

\author{
A. Jeppsson ${ }^{1 *} \mathbb{D}$, Mikko Höltta $^{2}$, H. Zetterberg ${ }^{2,3,4}$, K. Blennow ${ }^{2,3}$, C. Wikkels $\varnothing^{1}$ and Mats Tullberg ${ }^{1}$
}

\begin{abstract}
Background: Patients with idiopathic normal pressure hydrocephalus (iNPH) have reduced cerebrospinal fluid (CSF) concentrations of amyloid- $\beta$ (A $\beta$ ) and $\alpha$ - and $\beta$-cleaved soluble forms of amyloid precursor protein (SAPPa and sAPP $\beta$ ). The aims of this study were to examine if changes could also be seen in the CSF for secreted metabolites of APP-like protein 1 (APLP1) and to explore the prognostic value of amyloid-related CSF biomarkers, as well as markers of neuronal injury and astroglial activation, as regards to clinical outcome after shunt surgery.

Methods: Twenty patients diagnosed with iNPH, 10 improved and 10 unchanged by shunt surgery, and 20 neurologically healthy controls were included. All patients were examined clinically prior to surgery and at 6-month followup after surgery using the iNPH scale. Lumbar puncture was performed pre-operatively. CSF samples were analyzed for neurofilament light (NFL), $A \beta$ isoforms $A \beta 38, A \beta 40$ and $A \beta 42$, SAPPa, SAPP $\beta, A P L P 1 \beta$-derived peptides APL1 $\beta 25$, APL1 $\beta 27$ and APL $1 \beta 28$ and YKL40 by immunochemical methods.

Results: The concentrations of all soluble forms of APP, all A $\beta$ isoforms and APL1 $\beta 28$ were lower, whilst APL1 $\beta 25$ and APL1 $\beta 27$ were higher in the CSF of iNPH patients compared to controls. There was no difference in biomarker concentrations between patients who improved after surgery and those who remained unchanged.

Conclusions: The reduced CSF concentrations of A $338, A \beta 40, A \beta 42$, sAPPa and SAPP $\beta$ suggest that APP expression could be downregulated in iNPH. In contrast, APLP1 concentration in the CSF seems relatively unchanged. The increase of APL1 $\beta 25$ and APL1 $\beta 27$ in combination with a slight decreased APL1 $\beta 28$ could be caused by more available $\gamma$-secretase due to reduced availability of its primary substrate, APP. The data did not support the use of these markers as indicators of shunt responsiveness.
\end{abstract}

Keywords: Neurodegeneration, Normal pressure hydrocephalus, Cerebrospinal fluid, Amyloid, NFL, YKL40, Prediction, APLP1

\section{Background}

Idiopathic normal pressure hydrocephalus (iNPH) is a condition with gait and balance disturbances, cognitive decline and urinary incontinence in combination with enlarged cerebral ventricles $[1,2]$. Shunt treatment improves more than $80 \%$ of the patients [3]. Without surgery, the clinical course is progressive and a delay in treatment means a loss of function that cannot be restored [4]. Being one of the few treatable neurodegenerative conditions, an accurate diagnosis and identification of patients

\footnotetext{
${ }^{*}$ Correspondence: anna.jeppsson@neuro.gu.se

${ }^{1}$ Hydrocephalus Research Unit, Institute of Neuroscience and Physiology, The Sahlgrenska Academy, University of Gothenburg, 41345 Gothenburg, Sweden

Full list of author information is available at the end of the article
}

who will benefit from shunt surgery is essential. The use of CSF biomarkers for such purposes has been identified as one of the priorities for hydrocephalus research [5].

Patients with iNPH exhibit suppressed CSF concentrations of amyloid- $\beta(A \beta)$ and the precursors soluble amyloid precursor protein $\alpha-$, and $\beta$ - $(\operatorname{sAPP} \alpha, \operatorname{sAPP} \beta)$, in combination with elevated neurofilament light protein (NFL) [6-9]. Hypothetically, this is thought to be due to a downregulation of APP in the periventricular tissue possibly caused by changed amyloid metabolism and/or a reduced clearance of extracellular fluid into CSF leading to lowered concentrations of APP-derived proteins in CSF [6].

Amyloid-like protein 1 (APLP1)-derived peptides are processed by similar enzymatic pathways as APP and share 
related structural domains and functions [10-12]. APLP1 is processed into short $A \beta$-like peptides (APL1 $\beta 25,1 \beta 27$ and $1 \beta 28)$ [13]. APLP1 is a substrate for the enzyme $\gamma$-secretase and the ratio of APLP1-derived APL1 $\beta 28$ to total APL1 $\beta$ is a surrogate marker for $A \beta 42$ production in the central nervous system [13, 14]. Recently, it was reported that $\gamma$-secretase was higher in brain biopsies from iNPH patients with amyloid plaques than in those without [15].

The aim of this study was to examine CSF concentrations of APLP1-derived peptides in iNPH, especially if the APL1 328 form was increased, and to explore the prognostic value of amyloid-related CSF biomarkers. For this purpose, we analyzed the APP-derived peptides sAPP $\alpha$, sAPP $\beta, A \beta 38, A \beta 40$ and A $\beta 42$, the APLP1derived peptides APL1 $\beta 25$, APL1 $\beta 27$ and APL1 $\beta 28$ in CSF in 20 patients with iNPH (10 improved and 10 unchanged by shunt operation) and 20 neurologically healthy controls.

\section{Methods}

\section{Study populations}

Ten iNPH patients improved after shunt surgery and 10 non-improved were retrospectively selected. All were diagnosed in accordance with the international guidelines [16]. The patients were selected from our local database at the hydrocephalus unit at Sahlgrenska University Hospital on the premises that full medical data pre- and postoperatively were available and that there was sufficient CSF stored to perform the analyses. In all, the database contained 176 patients. From the database, the 10 patients who benefitted the most from surgery (as defined by improvement in the iNPH scale) and fulfilled the inclusion criteria were selected. In the group that did not benefit from surgery, medical records were scanned in order to establish that at time for follow-up all shunts were working, none had complications and that that there be no other known cause for non-improvement. Patients who had complications that could be attributed to shunt surgery were excluded. In all, the groups were selected in order to magnify the difference in responsiveness to shunt surgery within the clinical material and analyze two clearly-distinguishable extreme groups as regards to shunt responsiveness.

The improved 10 patients consisted of five men and five women, aged $70.3 \pm 3.20$ (mean \pm SD) and the 10 unimproved patients ( $<5$ points at the iNPH scale) consisted of seven men and three women aged $71.6 \pm 8$ (mean $\pm S D)$. The groups did not differ significantly in terms of comorbidities, preoperative MMSE scores, extent of white matter lesions (WML), age or sickness duration. The baseline clinical data of the different groups are outlined in Table 1.

All patients were examined clinically prior to surgery and 6 months after by the iNPH scale, composed
Table 1 Clinical characteristics of iNPH patients at baseline

\begin{tabular}{llll}
\hline & $\begin{array}{l}\text { Improved } \\
\mathbf{n = 1 0}\end{array}$ & $\begin{array}{l}\text { Non-improved } \\
\mathbf{n}=\mathbf{1 0}\end{array}$ \\
\hline Age (mean \pm SD) & $70.3 \pm 3.2$ & $71.6 \pm 8.0$ & $\mathrm{~ns}$ \\
Sex (male/female) & $5 / 5$ & $7 / 3$ & $\mathrm{~ns}$ \\
Sickness duration (month) & $42 \pm 21$ & $34 \pm 28$ & $\mathrm{~ns}$ \\
Diabetes (y/n) & $2 / 8$ & $2 / 8$ & $\mathrm{~ns}$ \\
Hypertension (y/n) & $5 / 5$ & $6 / 4$ & $\mathrm{~ns}$ \\
Cardiovascular disease (y/n) & $2 / 8$ & $1 / 9$ & $\mathrm{~ns}$ \\
MMSE (median, IQ-range) & $23(22-28)$ & $26(24-28)$ & $\mathrm{ns}$ \\
WML (median, IQ-range) & $6(4-10)$ & $11(5-20)$ & $\mathrm{ns}$ \\
Evans index (median, IQ-range) & $0.43(0.38-0.46)$ & $0.39(0.36-0.41)$ & $\mathrm{ns}$ \\
\hline
\end{tabular}

of items assessing gait, cognition, continence and balance [17]. The extent of WML was rated by the Wahlund scale from MRI or CT scans at the time for diagnosis [18]. Lumbar puncture was performed preoperatively with the patient in recumbent position. In the improved group the median improvement was 26 points and in the non-improved group the median was 1 point (Table 2). All patients received a ventriculo-peritoneal shunt with a programmable valve with an anti-siphon device and a Rickham reservoir. All had working shunts and none had complications at the time for evaluation.

Twenty control subjects were chosen from a population of volunteers who had given consent to CSF sampling prior to knee surgery. The controls had no history of neurological or psychiatric disease, a normal clinical neurological examination and a normal mini-mental state examination score. They consisted of eight men and 12 women aged $71.2( \pm 6.4)$. There was no difference in age between the three subcategories (controls, iNPH improved and iNPH non-improved).

\section{CSF analyses}

Amyloid $\beta$ isoforms (A $\beta 38, A \beta 40$, and $A \beta 42)$ were analyzed by electrochemiluminescence assays (Meso Scale Discovery, Gaithersburg, MD, USA). The APLP1derived peptides APL1 $\beta 25$, APL1 $\beta 27$, and APL1 $\beta 28$ were analyzed using a commercial ELISA (IBL International, Hamburg, Germany). The samples were analyzed according to the kit insert with minor modifications. The CSF samples were diluted 1:20 for APL1 $\beta 25,1: 10$ for APL1 327 , and 1:5 for APL1 $\beta 28$ by the dilution buffer contained in the kit. All samples were analyzed in duplicate and the $\mathrm{CV} \%$ for standards and samples was $<5 \%$.

NFL was measured by ELISA technology using a commercial kit (NF-Light, UmanDiagnostics, Umeå, Sweden) with a lower limit of detection of $50 \mathrm{ng} / \mathrm{L}$. For astroglia activation, CSF YKL-40 concentration was measured by 
Table 2 iNPH scale score pre op, post op and outcome (median and IQ-range)

\begin{tabular}{|c|c|c|c|c|c|c|}
\hline & \multicolumn{2}{|l|}{ Pre op } & \multicolumn{2}{|l|}{ Post op } & \multicolumn{2}{|l|}{ Outcome } \\
\hline & $\begin{array}{l}\text { Improved } \\
n=10\end{array}$ & $\begin{array}{l}\text { Non-improved } \\
n=10\end{array}$ & $\begin{array}{l}\text { Improved } \\
\mathrm{n}=10\end{array}$ & $\begin{array}{l}\text { Non improved } \\
\mathrm{n}=10\end{array}$ & $\begin{array}{l}\text { Improved } \\
n=10\end{array}$ & $\begin{array}{l}\text { Non-improved } \\
\mathrm{n}=10\end{array}$ \\
\hline Gait domain & $33(16-48)$ & $54(35-69)$ & $84(57-100)$ & $50(34-81)$ & 49 (26 to 57 ) & -1 (-6 to 11$)$ \\
\hline Cognitive domain & $64(37-73)$ & $60(46-80)$ & $75(57-85)$ & $69(48-80)$ & $10(6$ to 21$)$ & $3(-6$ to 11$)$ \\
\hline Continence domain & $60(20-80)$ & $80(60-80)$ & $90(75-100)$ & $70(55-80)$ & $30(0$ to 45$)$ & $0(-20$ to 5$)$ \\
\hline Balance domain & $67(67-71)$ & $67(67-83)$ & $75(67-87)$ & $67(67-83)$ & $0(-4$ to 20$)$ & $0(-16$ to 0$)$ \\
\hline Total iNPH score & $50(36-64)$ & $63(56-70)$ & $77.3(71-87)$ & $64(52-71)$ & 26 (21 to 30$)$ & $1(-3$ to 3$)$ \\
\hline
\end{tabular}

solid phase sandwich ELISA (R\&D Systems, Inc., Minneapolis, Minnesota, USA) according to the manufacturer's instructions. All analyses were performed batch-wise on one occasion by board-certified laboratory technicians at the Clinical Neurochemistry Laboratory at Sahlgrenska University Hospital, Mölndal, Sweden. Intra-assay coefficients of variation were below $10 \%$.

\section{Statistics}

Non-parametric methods were used for analyses. For comparisons between two groups the Mann-Whitney $\mathrm{U}$ test was performed and for comparisons between the three subgroups, the Kruskal-Wallis test was performed. For comparison of two proportions, Fisher's exact test was used. For association between two independent variables, the Spearman rank order correlation was chosen. The level of significance chosen was $p=0.05$, if not otherwise stated. No correction for the mass-significance effect was made in order to avoid type II errors. Statistical analyses were made using IBM $^{\circledR}$ SPSS $^{\circledR}$ Statistics for Windows version 21 .

\section{Results}

CSF concentrations of sAPP $\alpha$, sAPP $\beta, A \beta 38, A \beta 40, A \beta 42$ and APL1 $\beta 28$ were significantly lower and APL1 $\beta 25$ and 27 significantly higher in iNPH patients compared to healthy controls. Levels of NFL and YKL 40 did not differ between iNPH patients and healthy controls (Table 3; Fig. 1). The APL1 $\beta 28 /$ total APL1 $\beta$ ratio and the A $\beta 42 /$ to total $\mathrm{A} \beta$ ratio was lower in patients with iNPH in comparison with healthy controls (Fig. 2).

There were no differences in any of the CSF biomarkers between improved and non-improved iNPH patients (Table 4).

\section{Discussion}

Our data showing substantially reduced CSF concentrations of $A \beta 38, A \beta 40, A \beta 42$, sAPP $\alpha$ and $\mathrm{sAPP} \beta$ in patients with iNPH, confirm earlier results $[6-9,11,19-22]$. In contrast, APLP1 in CSF was mildly but significantly, changed with an increase in APL1ß25 and APL1ß27 and a slight decrease of APL1 $\beta 28$, compared with controls. The ratios APL1 $128 /$ total APL1 $\beta$ and A $\beta 42 /$ total A $\beta$ were reduced in patients with iNPH. However, there were no differences in any CSF biomarker between improved and non-improved iNPH patients after treatment with shunt surgery.

This explorative study was in part designed to identify predictive alterations in the amyloid CSF pattern. We included two small groups representing iNPH patients that benefitted the most and those without any response to surgical treatment with shunting, in order to identify possible differences. However, we found no differences in CSF biomarkers between improved and non-improved patients. The low number of cases in each group may have been a limitation in this study. However, if there are subtle variances in CSF amyloid concentrations linked to responsiveness that could be identified in larger sample sets, we believe that these would be of minor clinical importance. Lumbar CSF as opposed to ventricular CSF was analysed to enhance the practical applicability of the generated results. Ventricular CSF might however provide a different pattern as it probably mirrors brain metabolic processes more accurately.

The reduced CSF concentrations of $A \beta 38, A \beta 40, A \beta 42$, sAPP $\alpha$ and $\mathrm{SAPP} \beta$ in iNPH is consistent with earlier findings $[6,7,9,11,19-23]$, and compatible with a reduction in the concentrations of APP-derived proteins in the CSF of iNPH-patients. iNPH is a disorder of disturbed CSF dynamics and/or consequences thereof. Recent insights into the glymphatic system, has provided possibilities for a new route for clearance of excess fluid and interstitial metabolites, including $A \beta$, from the brain parenchyma $[24,25]$, together with clearance of $A \beta$ across the bloodbrain barrier $(\mathrm{BBB})$ via the LRP-1 receptor [26]. In the glymphatic system, there may be a para arterial influx of CSF from the subarachnoid space into the brain parenchyma where convective flow of interstitial fluid (ISF) helps to clear metabolic waste by para venous clearance towards the cervical lymph system, a system that seems to impair with aging $[25,27]$. However, clear evidence 
Table 3 Biomarker levels in iNPH and controls (median and IQ range)

\begin{tabular}{|c|c|c|}
\hline & $\begin{array}{l}\text { iNPH } \\
n=20\end{array}$ & $\begin{array}{l}\text { Controls } \\
n=20\end{array}$ \\
\hline NFL (ng/L) & $1185(731-2103)$ & $938(610-2141)$ \\
\hline APL1ß25 (ng/L) & $2591(2296-2951) \uparrow$ & $2180(1898-2386)^{* * *}$ \\
\hline APL1ß27 (ng/L) & $1083(887-1177) \uparrow$ & $874(796-964)^{* * *}$ \\
\hline APL1 $\beta 28$ (ng/L) & $1423(1317-1550) \downarrow$ & $1621(1422-1797)^{* *}$ \\
\hline$A \beta 38$ (ng/L) & $502(266-625) \downarrow$ & $1114(819-1445)^{* * *}$ \\
\hline$A \beta 40$ (ng/L) & $3676(2190-4748) \downarrow$ & $7682(6366-9809)^{* * *}$ \\
\hline$A \beta 42(n g / L)$ & $241(144-405) \downarrow$ & $754(493-1058)^{* * *}$ \\
\hline sAPPa (ng/mL) & $207(157-259) \downarrow$ & $416(323-665)^{* * *}$ \\
\hline sAPP $\beta(n g / m L)$ & $119(92-170) \downarrow$ & $280(182-389)^{* * *}$ \\
\hline YKL40 (ng/mL) & $122(90-167)$ & $137(104-177)$ \\
\hline
\end{tabular}

Arrows indicating biomarker levels in iNPH in comparison with controls ns non-significant

${ }^{*} p \leq 0.05 ;{ }^{* *} p \leq 0.01 ; * * * 0.001$ for this clearance is still lacking. In iNPH the CSF flow above the convexities is reduced and redirected into the ventricles and iNPH patients often present with a disproportionately enlarged subarachnoid-space $[28,29]$. These findings could hypothetically be in accordance with a disturbance of CSF/ISF exchange as the dilated paravascular spaces could impair CSF/ISF exchange. Although speculative, it could be hypothesized that the reduced concentrations of APP-derived proteins in the CSF of INPH patients could be due to stagnation of the flow in the periventricular ISF with reduced clearance of $A \beta$. This, however, remains to be proven. Regardless, levels of APPderived proteins in CSF are affected by both production and clearance of APP, and also by the ISF/CSF itself. This could make estimates of tissue levels in relation to CSF concentration problematic in patients with iNPH [30].

CSF APP-derived proteins increase after surgery, more in improved patients than in those that do not improve
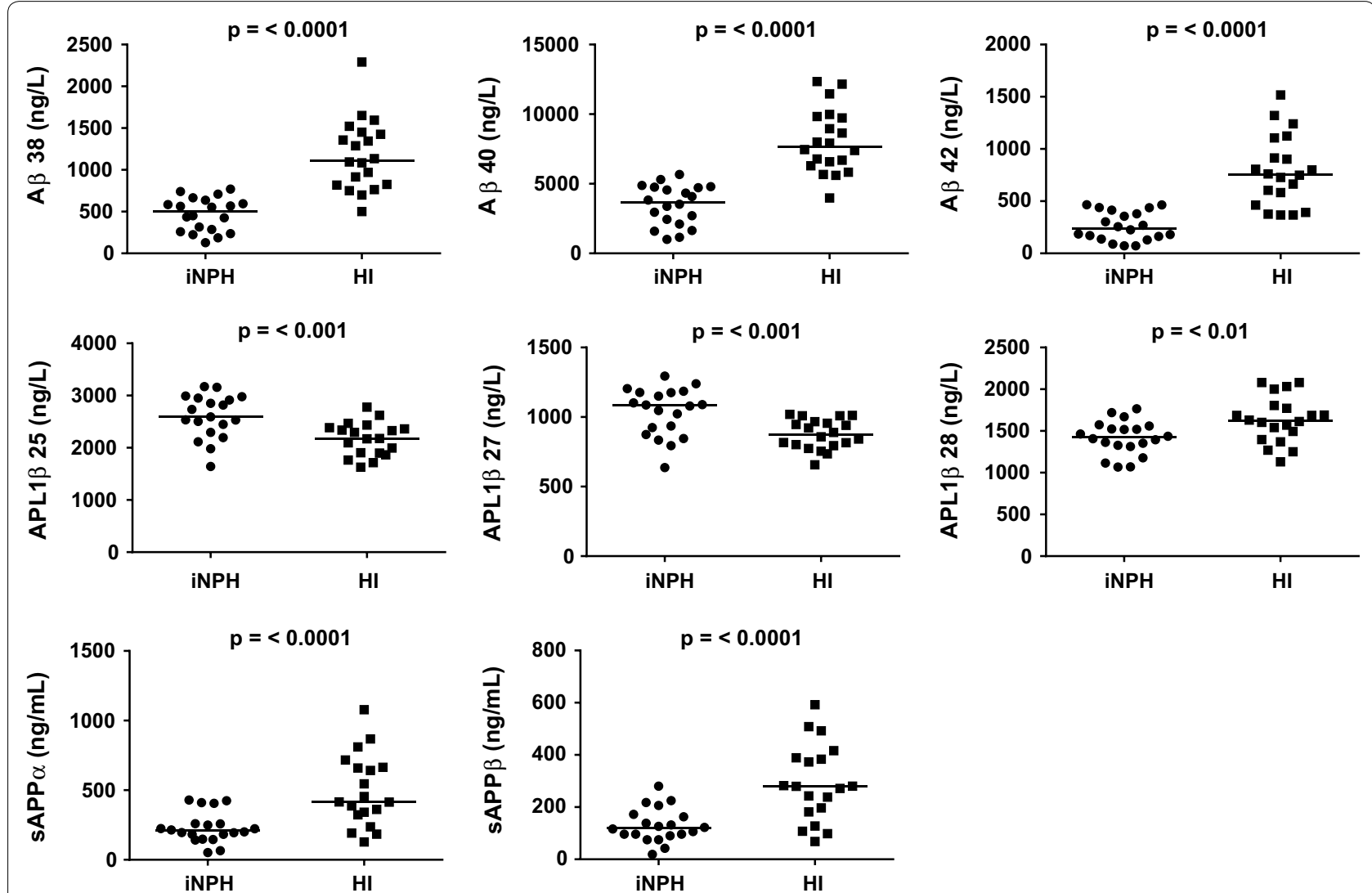

Fig. 1 Scatter plot showing CSF concentrations of Amyloids (Aß38, 40,42), APLP1 derivates (APL1 $\beta 25,27,28)$ and amyloid precursor proteins $(\mathrm{sAPPa}, \beta)$ in 20 patients with iNPH and 20 controls. Medians are indicated by horizontal lines. P values indicate the level of significance. The differences between the difference in concentrations of APLP1-derived proteins are, although statistically significant, more modest 

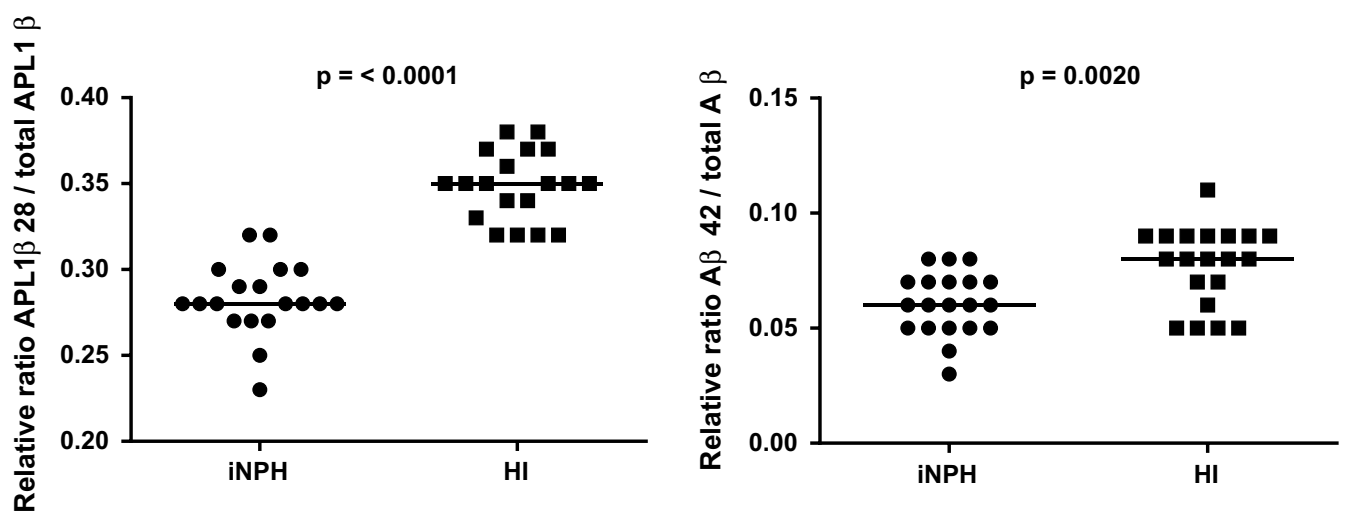

Fig. 2 The relative ratios of APL1 $\beta 28$ to total APL $1 \beta$ and $A \beta 42$ to total $A \beta$ in CSF in 20 patients with iNPH and 20 Controls. P values show the level of significance

Table 4 Levels of biomarkers in improved vs nonimproved iNPH patents (median and IQ-range)

\begin{tabular}{|c|c|c|c|}
\hline & $\begin{array}{l}\text { Improved } \\
\mathrm{n}=10\end{array}$ & $\begin{array}{l}\text { Non-improved } \\
n=10\end{array}$ & \\
\hline NFL (ng/L) & 1186 (869-1670) & 1085 (699-2432) & ns \\
\hline APL1 325 (ng/L) & 2532 (2174-2958) & 2820 (2401-2954) & ns \\
\hline APL1 $\beta 27$ (ng/L) & $1067(900-1157)$ & $1085(867-1214)$ & ns \\
\hline APL1 $\beta 28$ (ng/L) & 1423 (1264-1568) & $1458(1291-1562)$ & ns \\
\hline Aß38 (ng/L) & $500(308-605)$ & $503(224-677)$ & ns \\
\hline$A \beta 40$ (ng/L) & $3731(2642-4740)$ & 3677 (1522-4789) & ns \\
\hline$A \beta 42(n g / L)$ & $241(155-370)$ & $244(122-438)$ & ns \\
\hline sAPPa $(\mathrm{ng} / \mathrm{mL})$ & 205 (175-279) & $212(144-297)$ & ns \\
\hline $\mathrm{sAPP} \beta(\mathrm{ng} / \mathrm{mL})$ & $114(95-155)$ & $127(75-181)$ & ns \\
\hline YKL40 (ng/mL) & $122(99-153)$ & $134(84-180)$ & ns \\
\hline
\end{tabular}

ns non-significant

$[6,11]$. Even if not designed to analyze such changes, the present study does not contradict these findings. The presumed reduction in CSF concentrations of the amyloidderived proteins could reflect a pathophysiological aspect of iNPH that is not directly linked with prediction. The irreversibility in non-improved iNPH patients could be due to either tissue damage related to iNPH or damage related to other factors such as co-morbidities e.g. cerebrovascular lesions, as there was a tendency of more profound WML in the non-improved group even if not reaching statistical significance. However, cerebrovascular disease is not a negative predictor of outcome after shunt surgery [31].

Contrary to the profound alterations in APP metabolites, the APLP1-derived peptides showed only minor changes with a small elevation in APL1ß25 and APL1 $\beta 27$ and a slight reduction of APL1 $\beta 28$. APP and APLP1 are processed by the same enzymes, including $\gamma$-secretase $[10,12,13,32]$, and the results could indicate that the two substrates compete with each other at the active site of $\gamma$-secretase. If APP expression is reduced, as most data suggest it is in iNPH, there would be more $\gamma$-secretase available for the processing of APLP1. The processing occurs by $\gamma$-secretase cleaving at amino acid 28 of the membrane-spanning $\beta$-domain of APLP1 and then working its way towards the N-terminus of the protein. Increased processing of APLP1 by $\gamma$-secretase would thus result in decreased concentration of APL1 $\beta$ and increased concentrations of the shorter forms $[33,34]$. This is exactly what we observe in iNPH. Over-expression of APP results in a decrease of APL1 $\beta$, which supports this substrate competition hypothesis [35].

There is a difference in APP-metabolite production pattern between $\mathrm{iNPH}$ and AD. In $\mathrm{iNPH}$ there is a general suppression of APP-metabolites in CSF whereas in AD, there is an isolated $A \beta 42$ reduction, whereas the other $A \beta$-isoforms are unaffected [36]. Moreover, the internal composition of $A \beta$ production differs as shown in the APL1 $\beta 28 /$ total APL1 $\beta$ ratio. In our opinion, this provides further evidence against a common pathological etiology and might aid in the differential diagnosis of iNPH from AD by CSF biomarkers [37].

\section{Conclusions}

This data lends further support to a diagnostic profile in iNPH consisting of a general reduction in CSF concentration of APP-derived proteins. That the amyloid-like proteins behave in a different pattern could support the specificity and importance of the APP-down-regulation in iNPH. The study indicates that the biomarker profile in iNPH is consistent between patients who improve by shunt insertion and those who do not; therefore, our 
results do not lend support to the idea that these markers can be used for predictive purposes, but rather as an aid in the diagnosis of iNPH. Further studies will be needed to replicate the results and to expand the knowledge on the role of a possible altered amyloid metabolism for the pathogenesis of iNPH and the potential use of markers of amyloid metabolism to identify shunt responders needs to be further elucidated.

\section{Abbreviations}

iNPH: idiopathic normal pressure hydrocephalus; CSF: cerebrospinal fluid; $A B$ : amyloid- $\beta$; sAPPa: $a$-cleaved soluble forms of amyloid precursor protein; SAPP $\beta$ : $\beta$-cleaved soluble forms of amyloid precursor protein; APLP1: APP-like protein 1; APL1 $\beta$ : APLP1 $\beta$-derived A -like peptide; NFL: neurofilament light; WML: white matter lesion; ISF: interstitial fluid; BBB: blood-brain barrier.

\section{Authors' contributions}

AJ carried out the statistical analysis, participated in the design of the study and conceived the study, drafted the manuscript and participated in the coordination of the study. MK, $\mathrm{HZ}$ and $\mathrm{KB}$ carried out the laboratory analysis, participated in the design of the study and conceived the study. CW and MT conceived of the study and participated in the design and coordination and helped to write the manuscript. All authors read and approved the final manuscript.

\section{Author details}

1 Hydrocephalus Research Unit, Institute of Neuroscience and Physiology, The Sahlgrenska Academy, University of Gothenburg, 41345 Gothenburg, Sweden. ${ }^{2}$ Department of Psychiatry and Neurochemistry, Institute of Neuroscience and Physiology, the Sahlgrenska Academy, University of Gothenburg, Gothenburg, Sweden. ${ }^{3}$ Clinical Neurochemistry Laboratory, Sahlgrenska University Hospital, Molndal, Sweden. ${ }^{4}$ Department of Molecular Neuroscience, UCL Institute of Neurology, Queen Square, London, UK.

\section{Acknowledgements}

The authors would like to thank the patients, and the staff at the Hydrocephalus Research Unit and the Clinical Neurochemistry Laboratory, especially Per Hellström who provided highly valuable help on statistical and clinical matters.

\section{Competing interests}

K. B. has served as a consultant and at advisory boards for IBL International, Fujirebio Europe and Roche Diagnostics. C. W. receives honoraria for lecturing and consulting by Codman, Johnson and Johnson. The other authors have no competing interests.

\section{Availability of data and materials}

Data will not be shared as all data are already presented in the main paper.

\section{Ethics, consent and permissions}

The study was approved by the Regional Ethical Review Board in Gothenburg (Dnr 020-07) and written informed consent was given by the patient and/or a family member.

\section{Study funding}

This study was supported by grants from the Swedish Research Council, the European Research Council, Swedish State Support for Clinical Research (LUA-ALF), the Knut and Alice Wallenberg Foundation, the Torsten Söderberg Foundation, the Swedish Brain Foundation, Frimurarestiftelsen, the Göteborg Foundation for Neurological Research and the Neurological Research Foundation. The sponsors were not involved in the study design, in the collection, analysis and interpretation data; in the writing of the report; or in the decision to submit the paper for publication.

Received: 24 May 2016 Accepted: 18 July 2016

Published online: 29 July 2016

\section{References}

1. Hakim S, Adams RD. The special clinical problem of symptomatic hydrocephalus with normal cerebrospinal fluid pressure. Observations on cerebrospinal fluid hydrodynamics. J Neurol Sci. 1965;2:307-27.

2. Fisher CM. The clinical picture in occult hydrocephalus. Clin Neurosurg. 1977;24:270-84.

3. Klinge P, Hellström P, Tans J, Wikkels $\varnothing$ C. One-year outcome in the European multicentre study on iNPH. Acta Neurol Scand. 2012;126:145-53.

4. Andrén K, Wikkelsø C, Tisell M, Hellström P. Natural course of idiopathic normal pressure hydrocephalus. J Neurol Neurosurg Psychiatry. 2014:85:806-10.

5. McAllister JP, Williams MA, Walker ML, Kestle JRW, Relkin NR, Anderson AM, et al. An update on research priorities in hydrocephalus: overview of the third National Institutes of Health-sponsored symposium "opportunities for hydrocephalus research: pathways to better outcomes". J Neurosurg. 2015;123:1427-38

6. Jeppsson A, Zetterberg H, Blennow K, Wikkelsø C. Idiopathic normal-pressure hydrocephalus Pathophysiology and diagnosis by CSF biomarkers. Neurology. 2013;80:1385-92.

7. Miyajima M, Nakajima M, Ogino I, Miyata H, Motoi Y, Arai H. Soluble amyloid precursor protein $\mathrm{a}$ in the cerebrospinal fluid as a diagnostic and prognostic biomarker for idiopathic normal pressure hydrocephalus. Eur J Neurol. 2013;20:236-42.

8. Ågren-Wilsson A, Lekman A, Sjöberg W, Rosengren L, Blennow K, Bergenheim AT, et al. CSF biomarkers in the evaluation of idiopathic normal pressure hydrocephalus. Acta Neurol Scand. 2007;1 16:333-9.

9. Ray B, Reyes PF, Lahiri DK. Biochemical studies in normal pressure hydrocephalus (NPH) patients: change in CSF levels of amyloid precursor protein (APP), amyloid-beta (Aß) peptide and phospho-tau. J Psychiatr Res. 2011;45:539-47.

10. Eggert S, Paliga K, Soba P, Evin G, Masters CL, Weidemann A, et al. The proteolytic processing of the amyloid precursor protein gene family members APLP-1 and APLP-2 involves $\alpha-, \beta-, \gamma$-, and $\varepsilon$-Like cleavages: modulation of APLP-1 processing by N-glycosylation. J Biol Chem. 2004:279:18146-56.

11. Moriya M, Miyajima M, Nakajima M, Ogino I, Arai H. Impact of cerebrospinal fluid shunting for idiopathic normal pressure hydrocephalus on the amyloid cascade. PLoS One. 2015;10(3):e0119973.

12. Jacobsen $K T$, lverfeldt $K$. Amyloid precursor protein and its homologues: a family of proteolysis-dependent receptors. Cell Mol Life Sci. 2009;66:2299-318.

13. Yanagida K, Okochi M, Tagami S, Nakayama T, Kodama TS, Nishitomi K, et al. The 28-amino acid form of an APLPI-derived A $\beta$-like peptide is a surrogate marker for $A \beta 42$ production in the central nervous system. EMBO Mol Med. 2009;1:223-35.

14. Tagami S, Okochi M, Yanagida K, Kodama T, Arai T, Kuwano R, et al. Relative ratio and level of amyloid- $\beta 42$ surrogate in cerebrospinal fluid of familial alzheimer disease patients with presenilin 1 mutations. Neurodegener Dis. 2014;13:166-70.

15. Laiterä T, Sarajärvi T, Haapasalo A, Puli L, Kauppinen T, Mäkinen P, et al. Increased $\gamma$-secretase activity in idiopathic normal pressure hydrocephalus patients with $\beta$-amyloid pathology. PLoS One. 2014;9(4):e93717.

16. Relkin N, Marmarou A, Klinge P, Bergsneider M, Black PM. Diagnosing idiopathic normal-pressure hydrocephalus. Neurosurgery. 2005;57:S4-16 (discussion ii-v).

17. Hellström P, Klinge P, Tans J, Wikkelsø C. A new scale for assessment of severity and outcome in iNPH. Acta Neurol Scand. 2012;126:229-37.

18. Wahlund LO, Barkhof F, Fazekas F, Bronge L, Augustin M, Sjögren M, et al. A new rating scale for age-related white matter changes applicable to MRI and CT. Stroke. 2001;32:1318-22.

19. Tarnaris A, Toma AK, Pullen E, Chapman MD, Petzold A, Cipolotti L, et al. Cognitive, biochemical, and imaging profile of patients suffering from idiopathic normal pressure hydrocephalus. Alzheimers Dement. 2011;7:501-8.

20. Lins H, Wichart I, Bancher C, Wallesch CW, Jellinger KA, Rösier N. Immunoreactivities of amyloid $\beta$ peptide(1-42) and total t protein in lumbar cerebrospinal fluid of patients with normal pressure hydrocephalus. J Neural Transm. 2004;111:273-80.

21. Hulstaert F, Blennow K, Ivanoiu A, Schoonderwaldt HC, Riemenschneider M, De Deyn PP, et al. Improved discrimination of AD patients using B-amyloid (1-42) and tau levels in CSF. Neurology. 1999;52:1555-62. 
22. Kapaki EN, Paraskevas GP, Tzerakis NG, Sfagos C, Seretis A, Kararizou E, et al. Cerebrospinal fluid tau, phospho-tau181 and $\beta$-amyloid 1-42 in idiopathic normal pressure hydrocephalus: a discrimination from Alzheimer's disease. Eur J Neurol. 2007;14:168-73.

23. Leinonen V, Menon LG, Carroll RS, Dello lacono D, Grevet J, Jääskeläinen JE, et al. Cerebrospinal fluid biomarkers in idiopathic normal pressure hydrocephalus. Int J Alzheimers Dis. 2011;2011:312526. doi:10.4061/2011/312526

24. Xie L, Kang H, Xu Q, Chen MJ, Liao Y, Thiyagarajan M, et al. Sleep drives metabolite clearance from the adult brain. Science. 2013;342:373-7.

25. Iliff JJ, Wang M, Liao Y, Plogg BA, Peng W, Gundersen GA, et al. A paravascular pathway facilitates CSF flow through the brain parenchyma and the clearance of interstitial solutes, including amyloid beta. Sci Transl Med. 2012;4:147ra11.

26. Shibata M, Yamada S, Ram Kumar S, Calero M, Bading J, Frangione B, et al. Clearance of Alzheimer's amyloid- $\beta$ 1-40 peptide from brain by LDL receptor-related protein-1 at the blood-brain barrier. J Clin Invest. 2000;106:1489-99.

27. Kress BT, lliff JJ, Xia M, Wang M, Wei HS, Zeppenfeld D, et al. Impairment of paravascular clearance pathways in the aging brain. Ann Neurol. 2014;76:845-61.

28. Hashimoto M, Ishikawa M, Mori E, Kuwana N. Diagnosis of idiopathic normal pressure hydrocephalus is supported by MRI-based scheme: a prospective cohort study. Cerebrospinal Fluid Res. 2010;7:1.

29. Larsson A, Arlig A, Bergh AC, Bilting M, Jacobsson L, Stephensen H, et al. Quantitative SPECT cisternography in normal pressure hydrocephalus. Acta Neurol Scand. 1994;90:190-6.
30. Laiterä T, Kurki MI, Pursiheimo JP, Zetterberg H, Helisalmi S, Rauramaa T, et al. The expression of transthyretin and amyloid- $\beta$ protein precursor is altered in the brain of idiopathic normal pressure hydrocephalus patients. J Alzheimers Dis. 2015;48:959-68.

31. Tullberg M, Jensen C, Ekholm S, Wikkelsø C. Normal pressure hydrocephalus: vascular white matter changes on MR images must not exclude patients from shunt surgery. AJNR Am J Neuroradiol. 2001;22:1665-73.

32. Sjödin S, Andersson KKA, Mercken M, Zetterberg H, Borghys $H$, Blennow $K$, et al. APLP1 as a cerebrospinal fluid biomarker for $\gamma$-secretase modulator treatment. Alzheimers Res Ther. 2015;7:1.

33. Portelius E, Price E, Brinkmalm G, Stiteler M, Olsson M, Persson R, et al A novel pathway for amyloid precursor protein processing. Neurobiol Aging. 2011;32:1090-8

34. Selkoe DJ, Wolfe MS. Presenilin: running with scissors in the membrane Cell. 2007;131:215-21.

35. Portelius E, Hölttä M, Soininen H, Bjerke M, Zetterberg $H$, Westerlund A, et al. Altered cerebrospinal fluid levels of amyloid $\beta$ and amyloid precursor-like protein 1 peptides in Down's syndrome. Neuromol Med. 2014;16:510-6.

36. Blennow K, Hampel H. CSF markers for incipient Alzheimer's disease. Lancet Neurol. 2003;2:605-13.

37. Graff-Radford NR. Alzheimer CSF biomarkers may be misleading in normal-pressure hydrocephalus. Neurology. 2014;83:1573-5.

\section{Submit your next manuscript to BioMed Central and we will help you at every step:}

- We accept pre-submission inquiries

- Our selector tool helps you to find the most relevant journal

- We provide round the clock customer support

- Convenient online submission

- Thorough peer review

- Inclusion in PubMed and all major indexing services

- Maximum visibility for your research

Submit your manuscript at www.biomedcentral com/submit 